\title{
O PONTO DA CRÍTICA DE WILHELM DILTHEY às filosofias especulativas da História no Livro I da Introdução às Ciências do Espirito
}

\author{
GUILHERME JOSÉ SANTINI DA SILVA \\ Instituto Federal de Mato Grosso \\ Guarantã do Norte | Mato Grosso | Brasil \\ gjsantini@gmail.com \\ orcid.org/0000-0003-3225-6644
}

O artigo procura elucidar a crítica de Wilhelm Dilthey às filosofias especulativas da História, contida no Livro I do texto Introducão às Ciências do Espirito, a fim de esclarecer qual é sua razão. Assenta-se sobre a hipótese de que a crítica diltheyana às filosofias da História é um momento de primeira importância no desenvolvimento de sua argumentação sobre o devido modo de oferecer uma justificação epistemológica do conhecimento histórico. O estudo conclui que o erro das filosofias especulativas da História, para Dilthey, se deve ao fato de que em seus diferentes momentos, de Bossuet a Comte, ao tentar reduzir a multiplicidade dos fenômenos históricos a um princípio de unidade, as filosofias da História ignoram em tais fenômenos o seu conteúdo vivenciado, tendo postulado um conceito de racionalidade equivocado, produzindo um conhecimento intelectualista e sem utilidade; mas servem de contraponto para endossar a argumentação de Dilthey sobre a necessidade de uma reflexão da natureza do conhecimento histórico que postule outros pressupostos.

Wilhelm Dilthey - epistemologia da história filosofia da história 


\title{
THE POINT OF WILHELM DILTHEY'S CRITIQUE on speculative philosophies of history in the Book I of the Introduction to the Human Sciences
}

\author{
GuilHERME JOSÉ SANTINI DA SILVA \\ Instituto Federal de Mato Grosso \\ Guarantã do Norte | Mato Grosso | Brazil \\ gjsantini@gmail.com \\ orcid.org/0000-0003-3225-6644
}

The paper seeks to elucidate Wilhelm Dilthey's criticism of the speculative philosophies of History contained in Book I of the text Introduction of Human Sciences, in order to clarify his reason. It is based on the hypothesis that Dilthey's critique of the philosophies of History is an important moment in the development of his argument about the proper way to offer an epistemological justification of historical knowledge. The study concludes that the error of the speculative philosophies of History, for Dilthey, is due to the fact that in their different moments, from Bossuet to Comte, in trying to reduce the multiplicity of historical phenomena to a principle of unity, the philosophies of History ignore in such phenomena its lived content, having postulated a mistaken concept of rationality, producing an intellectualist and useless knowledge; but their serve as a counterpoint to endorse Dilthey's argument about the need for a reflection on the nature of historical knowledge that postulates other assumptions. 


\section{INTRODUÇÃO}

Na segunda metade do século XIX, o apelo pelo reconhecimento da cientificidade da História moveu historiadores e filósofos a teorizarem sobre o conhecimento histórico em relação a sua finalidade e racionalidade próprias. Datam desse período textos lidos até hoje em disciplinas de Teoria da História, de autores como Ranke, Droysen, Seignobos. Entre as obras do mesmo gênero encontra-se, menos citada, mas não menos importante, a Introdução às Ciências do Espirito, de Wilhelm Dilthey. Escrita em $1883^{1}$, a Introdução - como será tratada doravante -, contém toda uma argumentação sobre o devido modo de fundar a cientificidade das chamadas "Ciências do Espírito", sendo que, na medida em que tais Ciências fazem uso do conhecimento histórico, significa que o texto encerra reflexões sobre a justificação epistemológica do conhecimento histórico.

O texto da Introdução foi escrito e publicado a toque de caixa ${ }^{2}$, logo após Dilthey assumir a cátedra na Universidade de Berlim que pertencera a Hermann Lotze - a mesma que em gerações anteriores fora ocupada por Hegel. Dilthey assume a cátedra no ano de 1882. Ato contínuo, fez publicar o texto, ainda inconcluso. Consequentemente, a Introdução é um texto incompleto e não suficientemente organizado, mas dividido em duas partes, Livros I e II.

Diferente do Livro II, em que Dilthey disserta sobre as principais tentativas de fundamentação do conhecimento dos assuntos humanos segundo pressupostos metafísicos, da Antiguidade à Psicologia de Christian Wolff, o Livro I da Introdução encerra reflexões sobre a natureza do conhecimento histórico, com a defesa da necessidade de investigar os protocolos de sua racionalidade própria. De modo geral, sua pretensão é mostrar que o caminho para elevar o conhecimento histórico ao título de conhecimento de rigor, esclarecido epistemologicamente, consistia em renunciar a conceitos metafísicos, por um lado, e, por outro, evidenciar as categorias que configuram a experiência dos fenômenos propriamente humanos, ou seja, o fundamento lógico das Ciências do Espírito, postulada a qualidade de serem hermeneuticamente orientadas, portanto, epistemologicamente distintas das Ciências da Natureza.

Nesse itinerário do Livro I, é digno de nota que Dilthey se preocupe em fazer um levantamento crítico de projetos que tentaram dar ao conhecimento histórico um status rigoroso, habilitando-o a reduzir o múltiplo ao uno. Mais concretamente, é feito um exame crítico da chamada "filosofia da História", como ele próprio denomina, com a distinção de seus tipos, seus principais autores, seus equívocos e lacunas. Mas por qual razão o faz? Eis a pergunta que motiva o presente estudo.

Parte-se aqui da hipótese de que a crítica das filosofias da História não é ocasional, um artigo de erudição em meio ao texto, mas um momento que Dilthey assume como ponto de partida para desenvolver a partir dali a sua argumentação sobre o devido modo de oferecer uma fundamentação epistemológica do conhecimento histórico. Ao evidenciar o pecado original, por assim dizer, das filosofias da História, o autor da Introdução às Ciências do Espirito endossa a defesa da necessidade de uma reflexão sobre a natureza do conhecimento histórico que postule outro conceito de racionalidade e outras categorias da experiência do fenômeno histórico.

\footnotetext{
${ }^{1}$ Contido no tomo I das Gesammelte Schriften, as Obras Completas de Dilthey.

${ }^{2}$ Cf. Camilleri (2016, 27-28).
} 


\section{A EXPOSIÇÃO QUE DILTHEY FAZ DAS FiLOSOFIAS ESPECULATIVAS DA HistóRIA}

Em primeiro lugar, cumpre saber, dentro do recorte do Livro I da Introdução, a que Dilthey se refere quando cita a "filosofia da História" (Philosophie der Geschichte) ${ }^{3}$. Mas ele mesmo dá uma definição, distinguindo três modalidades e uma derivação consequente das três.

Por filosofia da História, entendo uma teoria que procura compreender a conexão da efetividade histórica por meio de uma unidade correspondente de proposições conexas. Esse sinal característico da unidade do pensamento é indivisível de uma teoria que tenha por meta distintiva o conhecimento da conexão total. A filosofia da História encontrou essa unidade ora em um plano do decurso histórico, ora em um pensamento de fundo (uma ideia), ora em uma fórmula ou em uma conexão de fórmulas que exprimem a lei do desenvolvimento. A Sociologia (aqui, eu falo apenas da Escola Francesa) incrementa ainda essa pretensão do conhecimento em nome de uma direção científica da sociedade.

(GS I, 934).

Ou seja, Dilthey se refere inquestionavelmente às chamadas "filosofias especulativas da História", segundo a expressão consagrada depois por Raymond Aron ${ }^{5}$. Em outras palavras, Dilthey faz menção àquelas formulações totalizantes dos acontecimentos humanos que têm por objetivo reduzir a multiplicidade dos acontecimentos a uma unidade que os explique de uma vez por todas e simplesmente, unidade concebida - como ele irá expor - ao modo de uma abstração, pela redução do múltiplo ao uno ${ }^{6}$, e, na sequência, oferece ao leitor uma breve história dessa linhagem de pensamento, que teria sido criada pela Teologia, conforme o objetivo de dar ao homem uma noção unitária da história humana.

\footnotetext{
${ }^{3}$ Uma vez que, tanto para o leitor do século XXI quanto para o leitor coetâneo a Dilthey, o conceito de "filosofia da História" guarda uma equivocidade intrínseca. Como destaca Vasicek: "A "Filosofia da História" possui vários sinônimos correlatos, nomeadamente: história filosófica, filosofia histórica, (meta)teoria da história, história teorética, lógica da história, metahistória, historiosofia, e historiografia anacrônica. Em outros tempos, o termo histoire raisonnée ou história conjectural foi popular. Há pouco consenso sobre a terminologia, mas cada uma dessas expressões indica algum tipo de relação entre Filosofia e História - uma relação problemática, já que os termos representam uma oposição, não diferente daquela que há entre sincronia e diacronia, generalidade e singularidade, ou holismo e individualismo" (Vasicek 2009, 26).

${ }^{4}$ A referência ao texto de Dilthey é feita na forma acadêmica dos Dilthey-Studien, conforme a abreviação das Gesammelte Schriften (GS), seguida do número do respectivo tomo.

${ }^{5}$ Raymond Aron faz uma conhecida distinção, desde seu texto de juventude A Filosofia Crítica da História (1938), entre duas tipologias de pensamento filosófico da História: uma aplicada à História enquanto conjunto dos acontecimentos humanos no tempo, e a outra aplicada à História enquanto produto da compreensão humana de tais acontecimentos, como um ramo da Teoria do Conhecimento. A primeira seria, em suas palavras, a "filosofia especulativa da História"; a segunda, a "filosofia crítica da História". Essa distinção e nomenclatura veio a ser adotada na posteridade da tese de Aron por outros estudiosos do assunto, como Jan Patocka, David Walsh, Maurice Lagueux, Cassandra Roldán, e é seguida neste artigo.

${ }^{6}$ Que invoca, para o leitor de hoje acostumado ao tema, o plano de obras como História da Filosofia da História, de Johannes Thyssen, e O Sentido da História, de Karl Löwith.
} 
O pensamento de um plano unitário da história humana (...) foi criada pela Teologia. No início e ao fim de toda a história estariam dados pontos fechados para a sua construção: surge assim uma tarefa resolvível, a de extrair do decurso histórico do mundo o fio condutor do pecado original ao Juízo Final. (GS I, 98)

É apontada então uma obviedade: essa linhagem de pensamento começa com Agostinho de Hipona; com $A$ Cidade de Deus, a grande referência dessa interpretação teológica da História. Seu principal elemento destacado por Dilthey é o sentido unitário que a visão histórica adquire.

Teria sido esse sentido unitário sobre o tempo histórico e a humanidade, que apresentam ao homem, na sua individualidade, uma conexão entre as diferentes histórias, e que revela um sentido para sua própria história pessoal, o legado dessa filosofia teológica da História, fundamentada metafisicamente. A ela estão ligadas por herança as "aspirações do século XVIIP" (GS I, 99), representadas nas filosofias da História de Condorcet e Turgot, e cujo traço de união é feito por Bossuet, com seu Discurso sobre a História Universal, também citado. A ideia de um sentido unitário da história ${ }^{7}$ que provê ao indivíduo o dimensionamento de todo o decurso histórico e da humanidade em um esquema unitário chega de Agostinho à Modernidade por meio de Bossuet; até que, no século XVIII, finalmente, há uma transformação decisiva, feita por Turgot. Turgot seculariza a filosofia teológica da História, diz Dilthey, procurando resolver a questão colocada por Bossuet sobre o plano divino da história dentro de um marco conceitual racionalista ${ }^{8}$. Teria sido por meio dessa imanentização do sentido teológico da História que o legado da visão unitária da história chega ao Iluminismo. A visão de uma unidade da história humana, outrora coberta pelo véu do mistério, interpretada em chave teológica, passa a ser interpretada em uma chave racionalista, para explicar a multiplicidade dos fenômenos e a conexão do indivíduo com a humanidade segundo uma ideia supostamente justificada, mas que ocorre dentro de um momento que é apenas a substituição de uma metafísica por outra. Dilthey diz:

O pensamento de um plano unitário no decurso histórico do mundo9 muda na medida em que se separa das premissas típicas do sistema teológico no século XVIII: sua realidade maciça torna-se um teatro de sombras ${ }^{10}$ metafísico. (...) Qual é o objetivo da laboriosa escalada da humanidade? Qual é a razão da pobreza no mundo? Por qual razão apenas uma minoria tem acesso ao progresso? Do ponto de vista de Agostinho, isso tudo é compreensível, mas do ponto de vista do século XVIII tudo isso é um enigma para cuja solução falta um claro ponto de apoio. Assim, toda tentativa do século XVIII em mostrar o plano e o sentido da história humana é apenas uma transformação do velho sistema. A educação do

\footnotetext{
${ }^{7}$ No presente artigo, será usada a expressão história com " $\mathrm{h}$ " sempre que se designar a história empírica, enquanto conjunto dos acontecimentos humanos no tempo e seu devir.

${ }^{8}$ Que em Bossuet, diga-se de passagem, é mantido na categoria teológica de mistério, embora tanto no Discurso sobre a História Universal quanto no Sermão sobre a Providência ele mencione expressamente um determinado ponto de vista a partir do qual a história humana deve ser observada. Neste último texto, a seguinte passagem é digna de nota por encerrar uma expectativa que um século depois tentará ser levada a cabo: “Talvez acheis que aquilo que parece confuso é uma arte velada; e se souberdes encontrar o ponto através do qual é preciso olhar as coisas, todas as desigualdades se retificarão e vereis somente sabedoria onde antes imagináveis desordem". (Bossuet 2006 [1662], 34).

${ }_{9}$ Dilthey quase repete exatamente a mesma frase utilizada uma página antes, com a qual começa a citação anterior.

10 A expressão traduzida como "teatro de sombras" é "Schattenspiel”: uma arte de contar histórias cujos personagens são sombras projetadas de outros objetos.
} 
gênero humano em Lessing, o autodesenvolvimento de Hegel, a mutação da organização hierárquica em Comte não são outra coisa. Haja vista que o corpo místico, que na Idade Média continha em si a conexão da história mundial, no modo de pensar do século XVIII se dissolve no indivíduo, então é preciso encontrar o substituto em uma representação que salvaguarde essa unidade da humanidade. (GS I, 99-100)

Também as ideias de razão universal e espírito do mundo, exemplifica Dilthey $\operatorname{logo}$ a seguir na mesma página, são apropriadas no século XVIII, mediante essa expectativa da unidade, que dê ao indivíduo a compreensão da história humana nela mesma e de sua relação com a humanidade. A justificação da história por meio da visão de sua unidade já se tornara um imperativo moral, observa Dilthey, razão de seu prestígio. Porém, não obstante queira reduzir a história, não obstante a multiplicidade de seus fenômenos, a uma unidade na forma de um sentido, de um plano, de uma ideia, ou ainda de uma conexão de leis ${ }^{11}$, cada uma dessas formulações remete a um esquema explicativo sempre carente de uma justificação epistemológica.

Cumpre não olvidar que tais formulações, das quais a Sociologia de Comte seria uma última derivação, são um assunto importante para Dilthey porque também são etapas da realização do propósito de elevar o conhecimento histórico a um grau científico, no sentido de levá-lo do estado artístico de uma narrativa presa às contingências ao status de um conhecimento rigoroso, apto a reduzir as contingências humanas a uma fórmula universalmente válida pela qual se possa explicar os acontecimentos, tão variados, tão cambiantes eles sejam.

O propósito de reduzir a multiplicidade a um princípio de unidade, entende Dilthey, em si mesmo não é ilegítimo; mas em relação ao estudo da efetividade histórica e social, isto é, dos fenômenos que a História estuda, sim. Dilthey é claro ao defender que a filosofia da História, dita de maneira geral, deve "renunciar à sua pretensão" (GS I, 95), querendo dizer com isso a pretensão comum às filosofias especulativas da História de reduzir a totalidade dos fenômenos sociais e históricos segundo um princípio de unidade fixo, em si mesmo a-histórico. Pretensão que em si pode ser válida, mas não em relação aos fenômenos dessa espécie.

Destaca-se, a seguir, uma crítica ainda mais aguda: Dilthey afirma que as generalizações que os diferentes ramos da filosofia da História oferecem como conhecimento são como o movimento circular das órbitas dos planetas na Astronomia ptolomaica e o princípio da força vital que servia à explicação da vida antigamente (GS I, 95-96).; e, indicando as teorias de Hegel, Schleiermacher e Comte como representantes dessas correntes, é taxativo ao chamar suas contribuições nesse quesito de "pretensiosos conceitos gerais" (GS I, 96) ${ }^{12}$. Em uma palavra, o que a filosofia da História apresenta não passa de uma generalização ${ }^{13}$ e se destaca da história vivida. "Para essa metafísica a efetividade tocante da vida é visivel apenas em sua silhueta como sombra" (GS I, 100-101).

${ }^{11}$ Passo necessário, em uma perspectiva prática, para a intervenção política. Essa necessidade de conhecer o sentido da história como um todo para haver uma Quadro Histórico dos Progressos do Espírito Humano, de Condorcet, em seu último capítulo.

12 Dilthey faz questão de expor a a-historicidade dos conceitos formulados por Hegel e Schleiermacher para deduzir o princípio unitário da história. O "Espírito" de um e a "Razão" de outro, diz ele, seriam uma "entidade abstrata que recapitula o decurso histórico do mundo em uma abstração incolor, um sujeito sem lugar e tempo, semelhante às mães de quem Fausto descende" (GS I, 105).

${ }^{13}$ Nesse sentido, a crítica de Dilthey alude imediatamente ao projeto crítico de Kant, partindo do fato das Ciências do Espírito hermeneuticamente orientadas, em nome de uma explicitação de suas condições lógicas de possibilidade. 
A crítica diltheyana à filosofia da História possui, nesse momento, uma dimensão pouco explorada. Não deixa de ser uma teoria negativa da Historiografia. Pois desse modo de ver a História, não se é capaz de vivenciar o próprio fenômeno, que não passa de matéria-prima para generalizações, especulações e deduções, sem alcançar seu conteúdo.

\begin{abstract}
Assim como as definições que são muito amplas são verdadeiras como proposições, mas falsas como definições, mesmo o que está escondido nas dobras de suas fórmulas toma cuidado para não ser incorreto, mas é apenas uma expressão miserável e insuficiente da poderosa efetividade da qual afirma expressar o conteúdo. (GS I, 96)
\end{abstract}

Dir-se-ia em outras palavras: que o modo de conhecer os fenômenos históricos praticado pelas diferentes vertentes da filosofia especulativa da História, consistindo em uma redução das contingências a uma abstração hipotética pela qual os elos entre os fenômenos e épocas, e povos e nações, uma vez explicados na forma de um esquema abstrato, diz a palavra final sobre o que a história como um todo significa; porém, sem que o conteúdo dos fenômenos seja submetido à experiência, representa uma narrativa oca, que é a expressão do intelecto genial do filósofo da História, mas não a expressão de uma história propriamente humana, impregnada do espírito humano ${ }^{14}$. Pode ser logicamente coerente; mas é inútil ${ }^{15}$.

A questão da utilidade do conhecimento histórico é uma constante no fundo da crítica diltheyana não menos digna de atenção. Quando Comte é citado em certo momento, por exemplo, Dilthey faz questão de frisar a inutilidade prática de suas formulações acerca da história. "Até seus conceitos gerais são ainda mais infecundos ${ }^{16 "}$ (GS I, 105). Sua Sociologia, Dilthey ensina, ao pressupor a naturalização da história humana, subordina-a aos métodos empregados pela Biologia, da qual aquela seria uma continuidade. Apresenta-se como Ciência de rigor; mas ao transplantar o método das Ciências da Natureza, instaura o conhecimento histórico nessa modalidade. Além disso, frisa o autor da Introdução às Ciências do Espírito, ao conceber os fenômenos da história humana por meio desses protocolos, oferece uma "notio universalis"; uma "abstração não-cientificica" (GS I, 107).

De modo geral, para Dilthey a pretensão da filosofia da História nos seus diversos ramos especulativos é ilegítima e inútil porque, no fundo, se ampara no falso pressuposto do conhecimento histórico como um conhecimento do qual o sujeito estaria desligado do objeto, vendo-o de fora, ou, mais precisamente, de cima. Torna-se um produto intelectual que pode até ser sofisticado; mas não

\footnotetext{
${ }^{14}$ Gadamer, na conferência Extensão e Limites da Obra de Wilhelm Dilthey, contida no opúsculo O Problema da Consciência Histórica, faz uma revisão sumária do projeto diltheyano da Crítica da Razão Histórica e toca nesse aspecto em que a crítica de Dilthey sobre o conhecimento histórico toma a dimensão de uma Teoria da Historiografia. Para Gadamer, uma vez que é a partir de pressupostos da Hermenêutica clássica que Dilthey pensa o conhecimento histórico, a verdade é concebida como compreensão da expressão; consequentemente, a história em si é incompreensível: não pode ser compreendida, ou seja, não pode ser conhecida, a não ser se pressuposta como um texto em relação ao qual o intérprete é um mediador (Gadamer 2003, $27-$ 38). Um mediador entre o que está para ser traduzido, pode-se dizer assim, e a sua tradução, dada como palavra também dotada de significado.

15 No mesmo texto supracitado, Gadamer diz: "Certamente, haverá sempre um meio de deduzir regras gerais dessa experiência, mas o sentido metodológico desse procedimento não autoriza a extrair daí uma lei propriamente dita, subsumindo-se de maneira unívoca um dado conjunto de casos concretos. As regras só são o que são com base no uso" (Gadamer 2003, 38).

${ }^{16}$ Aqui há uma comparação com Hegel e Schleiermacher, mencionados imediatamente antes.
} 
possui significado para o ser humano, em sua vivência temporal e finita; não revela a história como mundo ético porque a história, antes de tudo, está desprovida de vivência quando se a vê de fora ${ }^{17}$. Pela mesma razão é que a filosofia da História - inclusive suas derivações sociológicas -, não entra na categoria das Ciências do Espírito. A seguinte passagem, onde "sociedade" pode ser compreendida como conjunto dos fenômenos humanos, é esclarecedora. Diz Dilthey:

A natureza, para nós, é somente, de fato, algo externo, não algo interno. A sociedade é nosso mundo. Nela participamos, vivendo-a, em um jogo de influências recíprocas, com toda a força de nossa essência inteira, porque de dentro de nós mesmos, na mais viva inquietação, percebemos as condições e forças das quais seu sistema é constituído". (GS I, 36)

\section{O PONTO DA CRÍTICA DE DILTHEY À FILOSOFIA DA HISTÓRIA}

Portanto, o momento no qual a filosofia da História nos seus ramos especulativos teria a sua pretensão e utilidade abortadas seria o tipo de experiência que é pressuposto entre o sujeito do conhecimento e o fenômeno histórico $^{18}$. Ainda antes de iniciar sua história das filosofias da História, ele escreve, em passagem crucial, que:

Em tudo o que é humano há para nossa intuição um interesse que não é unicamente o da representação, mas do ânimo, da simpatia, do entusiasmo, em que Goethe viu com razão o mais belo fruto da contemplação histórica. A devoção faz do interior do verdadeiro historiador congenial com um universo que reflete todo o mundo histórico. Nesse universo de forças éticas, o único e o singular têm um significado completamente diferente do que na natureza externa. Concebê-lo não é um meio, mas um fim em si mesmo: pois a necessidade na qual se baseia é inextinguível e é dada com o que há de mais elevado em nosso ser. (GS I, 91)

17 A própria história é mutilada. O pensamento da história que é oferecido como a quintessência do conhecimento é uma mutilação da própria história, ainda que sofisticada. Em suas palavras: "Essas imagens abstratas dos filósofos da História", Dilthey diz, "apresentam o decurso histórico do mundo somente como uma abreviação variada” (GS I, 107).

${ }^{18}$ Será usado neste trabalho o conceito de "experiência" indiscriminadamente. Ao longo de sua vasta obra, Dilthey postula, ainda que sem descer a definições precisas, uma distinção entre dois modos de experiência: um chamado de "Erfahrung", outro de "Erlebnis". A experiência histórica seria uma experiência ao modo da "Erlebnis", traduzida mais frequentemente por "vivência" ou "revivência". Trocando em miúdos, resumindo uma distinção mais exaustiva de tais conceitos em Dilthey feita por O. F. Bollnow, diga-se que o primeiro caso, da "Erfahrung", é quando algo externo e estranho se dá como objeto à consciência (é uma substantivação do verbo "fahren", que designa o ato de estar em trânsito, logo, estar fora de um ambiente que nos seja familiar). Nesse caso, o núcleo da experiência não é quem faz a experiência, mas aquilo que o afeta. Já no caso da "Erlebnis", trata-se de uma substantivação do ato de viver ("leben"). No centro deste modo de experiência está quem vive. Está implícito a vivência de algo, evidentemente; mas é de algo que é meu/teu/nosso. É um dar-se. Tem em seu centro uma presença afetiva. Daí que a experiência histórica, para Dilthey, se dê originalmente como fato da consciência e não como mera representação. Ela é configurada como um dar-se de algo que no fundo já era meu ou nosso. (Cf. Bollnow 1970, 142-151). 
A verdadeira relação do sujeito ao objeto, no caso da experiência dos fenômenos humanos, teria sigo ignorada pelos filósofos especulativos da História, que conceberam tais fenômenos como coisa distante e autoproducente $^{19}$. Mas tal ingenuidade tem sua causa no conceito de racionalidade postulado pela filosofia da História, como uma faculdade que deve seu mérito à produção de conjecturas e operações indutivas e dedutivas, sem atenção para outros modos de intelecção. Dilthey contrasta a esse equívoco um conceito de racionalidade mais abrangente, que orientará a sua própria reflexão sobre a natureza do conhecimento histórico e seu fundamento, explicitado na afirmação seguinte: "a capacidade que opera nas Ciências do Espirito é o homem inteiro; as grandes atuações no âmbito dessa capacidade não dižem respeito à mera força da inteligência, mas a uma potência da vida pessoal' (GS I, 38). Para o filósofo de Biebrich, deve estar subentendido que uma justificação epistemológica do conhecimento histórico precisa considerar o modo próprio da experiência de um fenômeno humano, que não se dá, defende ele, como mera representação ${ }^{20}$, isto é, somente como dado sensível de algo externo a nós e independente de nós, mas como algo que é conato ao que sentimos em nossa própria interioridade afetiva e volitiva $^{21}$, o que remonta a um modo de racionalidade que é o próprio das Ciências do Espírito, mas que não é praticado pelas filosofias especulativas da História, razão de seu equívoco fundamental e de sua inutilidade.

O ponto da crítica diltheyana não diz respeito à expectativa de reduzir o múltiplo ao uno. De fato, Dilthey não defende o contingenciamento do conhecimento histórico a uma narrativa de fatos na sua singularidade. Também é feita uma crítica a uma prática historiográfica que não almeja o conhecimento de algo universal nos fenômenos humanos (cf. GS I, 90-91) 22. Mas o que há de universal em relação à multiplicidade cambiante dos fenômenos históricos não estaria acima da história nem na própria história mesma. Tratar-se-ia da própria subjetividade humana, precisamente das categorias subjetivas cuja atividade proporciona a experiência analógica em que se baseia a compreensão

19 Ou externa ao sujeito, e, poder-se-ia concluir, substancialmente independente; cujo princípio de unidade teria a si mesmo como causa e não a ação humana de pessoas de carne e osso. A percepção dessa hipostasiação que as filosofias especulativas da História fazem também é destacada por Koselleck em O Conceito de História: "[No fim do século XVIII] a fundamentação do Iluminismo histórico em uma História não mais derivada, mas na "História como tal", tinha se definido como conceito. A História se eleva a algo como uma última instância, ela se transforma em agente do destino humano ou do progresso social. (...) Há motivos para enxergar nessa nova conceitualização - que remete a História, como agens, a si mesma - a velada ou modificada Providência Divina, o que - naquilo que tange aos efeitos históricos - está correto". (Koselleck et al 2013, 124-125).

${ }^{20}$ Pois, diria Dilthey, no momento em que é revivido pelo sujeito, ao que é percebido de fora seria dado, pela própria subjetividade, segundo categorias pré-lógicas da empatia, da afetividade, ainda não suficientemente investigadas, atos que fazem com que aquele fenômeno venha a ser vivido novamente por outro alguém. Assim, no ponto da crítica de Dilthey à filosofia da História encontra-se também um momento-chave de sua revisão do conceito moderno de experiência e do representacionalismo que define a teoria do conhecimento da filosofia empirista.

${ }^{21}$ De outra maneira, dir-se-ia que para Dilthey os fenômenos históricos não podem ser concebidos como uma sucessão numérica, não podendo consequentemente ser concebidos segundo as mesmas categorias vigentes no pensamento científico-natural.

22 Quando, já no Prefácio da Introdução, Dilthey cita Comte, e também Buckle e Stuart Mill, reconhecendo o mérito de suas tentativas de estabelecer a cientificidade do conhecimento dos fenômenos humanos, justamente porque o conhecimento histórico não devesse ser subsumido a uma mera narrativa do que é particular, por mais significativo que certos fenômenos históricos sejam, é interessante que assim como ele não deixa de apontar a limitação de tais projetos, tampouco assume a posição de Carlyle "e outros espíritos vivazes" como satisfatória (GS I, XVII). 
hermenêutica do que alguém viveu como uma experiência que tem um sentido ético que eu mesmo posso reviver e compreender. É o que permitiria que aquilo que aconteceu uma vez possa ser traduzido agora, e a qualquer tempo, e pelos mais diversos indivíduos, como um significado válido trans-individualmente, $\mathrm{e}$ que pode ser ressignificado a cada época.

O sentido da história teria, então, uma natureza semântica ao invés de metafísica, substancial ou normativa ${ }^{23}$, postulando um conceito de racionalidade e experiência alternativo ao da Modernidade filosófica ${ }^{24}$. Por isso, o Livro I da Introdução às Ciências do Espírito termina com o chamado à necessidade de uma investigação dos "conteúdos psíquicos", da "conexão entre os atos psíquicos", de uma "análise da consciência"25 guiada pelo método introspectivo (GS I, 116-120); ou seja, com o chamado a uma nova Psicologia - que ele pretenderá desenvolver posteriormente ${ }^{26}-$, responsável por descrever e analisar as categorias subjetivas pelas quais o indivíduo se relaciona com o objeto histórico como seu. Seria uma reflexão "transcendental", todavia psicológica, que revelaria à disciplina histórica, entre outras, o fundamento de sua experiência e racionalidade próprias, a ampliar a investigação lógica, como ele próprio diz, do escopo normativo das Ciências Positivas para o escopo do pensamento discursivo (cf. GS I, 118).

\section{CONCLUSÃO}

Para Dilthey, estava claro que, se as Ciências dos fenômenos humanos, entre as quais se encontrava a História, permaneciam em um status protocientífico até o fim do século XIX, isso se dera pela falta de uma justificação epistemológica do conhecimento histórico que elas utilizam. Dilthey defende um determinado percurso para que essa justificação seja feita devidamente, respeitando a natureza autêntica do conhecimento histórico, ao longo da Introdução às Ciências do Espírito. Mas ele dirige a sua argumentação fazendo um contraponto às filosofias especulativas da História. Dilthey procura convencer o leitor do Livro I da Introdução de que, se as filosofias especulativas da História não elevaram o conhecimento histórico a um conhecimento de rigor, dando-lhe apenas uma aparência de cientificidade, foi por terem postulado um conceito de

\footnotetext{
${ }^{23}$ Embora essa não seja, como é comumente sabido, uma ideia original em Dilthey, mas uma herança da Hermenêutica alemã, que remonta imediatamente antes de si a Boeckh e Droysen.

24 Ato no qual atuam categorias da subjetividade ignoradas, dirá Dilthey em diversas passagens, pela filosofia moderna de Kant e Hume, que teriam postulado um único conceito de experiência e conhecimento.

25 O conceito de "consciência" (Bewusstsein) é um conceito-chave para compreender de maneira abrangente o ponto da crítica de Dilthey que se quer aclarar. Trata-se de um conceito de subjetividade em uma dimensão psicológica. Algo que já fica claro um esboço que serviu para a elaboração do texto da Introdução às Ciências do Espírito, quando Dilthey escreve sobre seu conceito de "consciência" dizendo que "fica excluída a restrição de seu sentido a processos de representação e da inteligência". (GS XIX, 59). Frithjof Rodi, ao tratar do estatuto da "consciência" em Dilthey diz que para entender o que Dilthey quer dizer com "consciência" cumpre ter em conta, antes de tudo, que os seus fatos, pelos quais a conhecemos, "não podem ser reduzidos a algo como uma esfera de imagens para um mero sujeito observador"; os chamados "fatos de consciência" "são também - e acima de tudo - experiências de dor, prazer, alegria, medo, satisfação, etc.” (Rodi 1989, 118).

26 De uma nova Psicologia que não postule os mesmos protocolos da Psicologia experimental, mas que descreva e analise os fatos da consciência tal como se dão em primeira pessoa, "sem referência a elementos hipotéticos e leis naturais", como resume Katherina Kinzel (cf. Kinzel 2019, 75), e que Dilthey procurará desenvolver posteriormente, no texto seminal Ideias para uma Psicologia Descritiva e Analítica (1894).
} 
racionalidade que, ao mesmo tempo em que oferece uma ilusão de rigor, oculta a necessidade de uma reflexão propriamente dita sobre o conhecimento histórico e seu fundamento. Esclarecer qual não é o verdadeiro modo de conhecer a história é uma tática adotada por Dilthey para endossar, pelo contraponto, a sua argumentação em favor de que a tarefa da justificação epistemológica do conhecimento histórico estivesse orientada por um conceito de racionalidade mais abrangente, tanto em relação ao que é postulado pelas filosofias da História quanto pelo que é postulado pela Filosofia Moderna, tributário da prática hermenêutica, e só podendo ser completada mediante uma investigação que revelasse o fundamento dessa mesma racionalidade que configura o histórico como ético, dotado de vida.

Para o autor da Introdução às Ciências do Espírito, as filosofias especulativas da História de Turgot, Hegel, Comte, entre outros, são equívocas e inúteis em sua pretensão à explicação da história inteira segundo um princípio de unidade, assim como em sua utilidade prática, porque suas formulações não passam, diz ele, de conceitos gerais abstratos. No entanto, a crítica de Dilthey converge para um ponto ainda mais determinante, que se quis elucidar. $\mathrm{O}$ ponto-chave é a questão sobre o modo como o fenômeno histórico é concebido. Quando a história é pensada como algo externo e substancialmente independente, vista de cima, sem correlato com o que é vivido pelo sujeito em primeira pessoa, seus fenômenos são apenas matéria-prima para conjecturas e operações indutivas e dedutivas. Em razão disso, a história pensada pela filosofia da História resulta em uma fabulação intelectualista, desprovida de significação ética. Mas a razão determinante da sua miopia é que o conceito de racionalidade postulado é o de uma racionalidade abstrata, cujas formulações repetem as especulações teológicas ou as operações típicas das Ciências da Natureza. Consequentemente, o fenômeno histórico não é reconstruído pela subjetividade humana como ocorre na prática hermenêutica, a experiência do histórico não é dotada de sentido ético, para a vivência humana.

A crítica às filosofias da História não é o único contraponto que Dilthey faz para apresentar a sua própria posição. Em outros momentos do mesmo texto, também no Livro I, Dilthey faz uma crítica à teoria do conhecimento da Filosofia Moderna, em virtude de seu representacionalismo e sua distinção radical entre sujeito e objeto. Mas o contraponto às filosofias especulativas da História não é menos importante.

Aqui, uma observação pontual. É digno de nota que, quando chega perto de conceituar o que seria o autêntico conhecimento histórico, Goethe seja citado. Não como exemplo de historiador, mas como alguém que tivesse visto qual é "o mais belo fruto da contemplação histórica"; que não seria uma abstração, um produto intelectualista, mas um interesse dotado de ânimo, simpatia, entusiasmo. $\mathrm{Na}$ visão histórica, o conteúdo do fenômeno deve ser vivenciado de dentro, por analogia do que já se encontra na interioridade do sujeito, havendo sempre no verdadeiro conhecimento histórico uma impregnação subjetiva. Assumido esse ponto de vista é que a história é concebível como mundo ético e a disciplina histórica pode ser útil para a vida prática dos indivíduos, povos e nações. Então, o ponto da crítica de Dilthey remonta, antes de tudo, ao fato de não ter havido, nas formulações das filosofias especulativas da História, uma reflexão epistemológica propriamente dita, ao modo de um questionamento do modo da relação entre sujeito e objeto no caso do conhecimento histórico, ausente, por conseguinte, a constatação da necessidade de uma reflexão das categorias da atividade subjetiva que configura essa relação, que será justamente a sua proposta como meio indispensável à realização do objetivo almejado: a justificação 
epistemológica do conhecimento histórico, e, finalmente, a fundação da cientificidade das Ciências do Espírito, evidenciada de uma vez por todas a sua racionalidade própria.

Finalmente, a crítica de Dilthey às filosofias especulativas da História significa também uma inflexão na história da filosofia da História, haja vista que, se até então a filosofia da História era conhecida da maneira como ele mesmo a conceitua, doravante a sua própria investigação no sentido de uma teoria não da história humana, mas do conhecimento histórico, cuja necessidade e importância ele afirmará até sua morte em 1909, abrirá caminhos para outros filósofos aplicados à mesma investigação, que já não é sobre o fazer historiográfico, mas sobre os fundamentos lógicos da concepção de sentido e valor históricos. Tratase da inauguração da corrente que Raymond Aron denominaria de "fillosofia crítica da História", e que ampliaria em um sentido ainda mais abrangente o próprio conceito de "filosofia da História".

\section{REFERÊNCIAS}

ARON, Raymond. La Philosophie Critique de l'Histoire. Paris: Julliard, 1970.

BARROS, José, D’A. Teorias da História e Filosofias da História? Reflexões sobre o contraste entre estes dois espaços de reflexão sobre o fazer histórico. In: Revista Anos 90, v. 19, (2012), p. 367-400.

BOLLNOW, O. F. Introducción a la Filosofía del Conocimiento. Buenos Aires: Editorial Amorrortu, 1970.

BOSSUET, J.-B. Sermão sobre a Providência. In: MENEZES, Edmilson (org.). História e Providência: Bossuet, Vico e Rousseau: textos e estudos. Ilhéus: Editora UESC, 2006, p. 29-49.

CAMILLERI, Sylvain. Dilthey et la "Critique de la Raison Historique": genèse et enjeux d'un projet inachevé. In: FAGNIEZ, G.; CAMILLERI, S. (org.). Dilthey et L'Histoire. Paris: Vrin, 2016, p. 27-41.

CONDORCET, Marquis de. Esquisse d'un Tableau des Progrès de l'Esprit Humain. Paris: Vrin, 1970.

DILTHEY, Wilhelm. Gesammelte Schriften, I. Göttingen: Vandenhoeck \& Ruprecht, 1957.

DILTHEY, Wilhelm. Gesammelte Schriften, V. Göttingen: Vandenhoeck \& Ruprecht, 1957.

DILTHEY, Wilhelm. Gesammelte Schriften, XIX. Göttingen: Vandenhoeck \& Ruprecht, 1997.

GADAMER, H.-G. O Problema da Consciência Histórica. Rio de Janeiro: Editora FGV, 2003.

KINZEL, Katherina. Relativism in German Idealism, Historicism and NeoKantianism. In: KUSCH, M. (ed.). The Routledge Handbook of Philosophy of Relativism. Abingdon: Routledge, 2019, p. 69-78.

KOSELLECK, Reinhart et al. O Conceito de História. Belo Horizonte: Autêntica, 2013

LAGUEUX, Maurice. Actualité de la Philosophie de l'Histoire: l'Histoire aux mains des philosophes. Québec: Presses de l’Université Laval, 2004.

LESSING, H.-U. Wilhelm Dilthey, o filósofo das Ciências Humanas. In: AoristoInternational Journal of Phenomenology, Hermeneutics and Metaphysics, n. 3, v. 1, 2019, p. 14 31.

LÖWITH, Karl. Historia del Mundo y Salvación: los presupuestos teológicos de la filosofia de la historia. Buenos Aires: Katz, 2007. 
PATOCKA, Jan. L'Europe après l'Europe. Lagrasse: Verdier, 2007.

PORTA, Mário. A. G. Estudos Neokantianos. São Paulo: Edições Loyola, 2011.

RODI, Frithjof. O conceito de estrutura em Dilthey. In: Revista USP, n. 2, 1989, p. $117-$ 124.

ROLDÁN, Concha. Entre Casandra y Clio: una historia de la filosofia de la historia. Madri: Akal Ediciones, 1997.

THYSSEN, Johannes. Historia de la Filosofia de la Historia. Buenos Aires: Espasa Calpe, 1954.

VASICEK, Zdenek. Philosophy of History. In: TUCKER, Aviezer (ed.). A Companion to the Philosophy of History and Historiography. Malden: Blackwell Publishing, 2009, p. 26-43.

WALSH, W. H. Introdução à Filosofia da História. Rio de Janeiro: Zahar Editores, 1978.

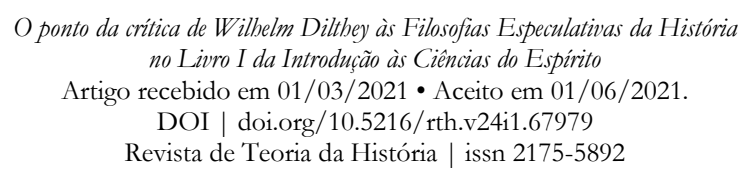

\section{cc}

Este é um artigo de acesso livre distribuído nos termos da licença Creative Commons Attribution, que permite uso irrestrito, distribuição e reprodução em qualquer meio, desde que o trabalho original seja citado de modo apropriado. 